\title{
Soy Protein Detection in Raw and Cooked Meat Products Using Different ELISA Kits
}

\author{
Cellerino Karina, Lopez Laura Beatriz \\ Faculty of Pharmacy and Biochemistry, Universidad de Buenos Aires - University of Buenos Aires, Buenos Aires, Argentina
}

\section{Email address:}

kcellerino@ffyb.uba.ar (C. Karina)

\section{To cite this article:}

Cellerino Karina, Lopez Laura Beatriz. Soy Protein Detection in Raw and Cooked Meat Products Using Different ELISA Kits. Journal of Food and Nutrition Sciences. Vol. 4, No. 6, 2016, pp. 170-174. doi: 10.11648/j.jfns.20160406.15

Received: September 23, 2016; Accepted: October 15, 2016; Published: January 4, 2017

\begin{abstract}
The aim of this study was to evaluate different ELISA kits for the detection of soy proteins in raw and cooked model systems (MS) added with soy protein concentrate $63 \%$ protein (SPC), and in commercial meat products. Nine bovine meat MS with 0-2000 ppm SPC, nine boneless ham cooked MS with 0-2000 ppm SPC and eight commercial meat products were analyzed. Three ELISA kits: Ridascreen ${ }^{\circledR}$ Fast Soya from R-Biopharm, Veratox ${ }^{\circledR}$ Quantitative Soy Allergen Test from Neogen and AgraQuant ${ }^{\circledR}$ Soy Assay from Romer were used. R-Biopharm kit detected above 5 ppm SPC in raw meat MS and above 10 ppm SPC in cooked boneless ham MS. Neogen kit detected above $250 \mathrm{ppm}$ SPC in both MS. Romer kit detected above 100 ppm SPC in raw meat MS and above 50 ppm SPC in cooked boneless ham MS. Results obtained using R-Biopharm and Veratox-Neogen kits were lower than real values. It is difficult to evaluate the correct quantification of Romer kit because the results are calculated as ppb soy trypsin inhibitor (STI). Results obtained for raw MS were higher than those obtained for cooked MS using R-Biopharm and Neogen kits, while results for raw MS were lower than those obtained for cooked MS using Romer kit. For one commercial sample that did not declare soy, results were below the quantification limits for the three kits used. For three commercial samples that did not declare soy, results were 22.3; 67.0 and $67.8 \mathrm{ppm}$ soy protein isolate respectively using Neogen kit. Results for four samples that did not declare soy were 448.0; 581.0 and $>1000$ ppb STI in two of them, using Romer kit. Two samples declared soy products, in one of them soy was detected with all kits, and in the other Neogen and Romer kits did not detect soy. In conclusion R-Biopharm kit was the most sensitive for the analysis of these samples. Thermal processing affected results for the kits used. It was possible to detect soy in commercial meat products that did not declare soy products. The food industry should be responsible for the declaration of soy in the labels of their products.
\end{abstract}

Keywords: Allergens, Soy, Meat Products, ELISA Kits

\section{Introduction}

Allergic diseases are given by a fault in the activation mechanisms or regulation of the immune response against innocuous antigens distributed in the environment. Food allergy is an abnormal immune response to a food or a food component. The prevalence is higher in children (4-8\%) than in adults (2-4\%) [1]. There are eight food groups (The Big-8) that are responsible for $90 \%$ of food allergies: milk, egg, soy, wheat, peanuts, tree nuts, fish and shellfish. A second group of allergenic foods has been defined; they are the "Second big-8": mustard, sesame, sunflower, cotton, molluscs, lentils, peas and poppies [1].

In the manufacture of meat products often extrinsic proteins as bovine or porcine plasma, soy products, different dairy products (caseinate, whey, skim milk powder, etc.), collagen, gelatin, are used [2]. These proteins work as water retention agents and emulsifying fats. They are good coagulants during cooking and improve shine and moisture of the product. Some of the proteins previously mentioned are food allergens and therefore constitute a risk for allergic patients, mainly when these proteins are not declared as ingredients in the food labels. According to the Argentine Food Code, all the ingredients used must be declared on the label [3]. However, in some products undeclared protein ingredients can be detected [4]. In Argentina the mandatory declaration of allergens in food labels was under revision [3]. In 2014 Food National Commission (CONAL) presented a document about the declaration of food allergens and substances that can cause adverse reactions in susceptible individuals, which must be 
declared following the list of ingredients label. In June 2016 the Food National Institute (INAL) presented a similar document. This document was in public consultation until July 8, 2016. Comments received during the public consultation were evaluated, the document was modified and it reached agreement. Now the project is in administrative procedure, soon it will be published in the Official Gazette and will be incorporated in Article 235 seventh of the Argentine Food Code [5, 6, 7].

There is a need of methodology that enables the detection of extrinsic allergenic proteins in meat products. The most common methodology for the analysis of food allergens is ELISA. In Argentina commercial kits are available from different companies. However, the cost of these kits is very high.

In Argentina it is common to add soy components to meat products, so the aim of this study was to evaluate different ELISA kits for the detection of soy proteins in raw and cooked model systems (MS) added with soy protein concentrate $63 \%$ protein (SPC), and in commercial meat products.

\section{Materials and Methods}

\subsection{Model Systems of Raw Meat and Cooked Boneless Ham}

Nine model systems of raw meat with the addition of SPC were prepared in the laboratory. The model systems were: 0 ; $5 ; 10 ; 50 ; 100 ; 250 ; 500 ; 1000$ and $2000 \mathrm{ppm}$ of SPC in mixture with raw meat.

Nine model systems of cooked boneless ham with the addition of SPC were prepared in the laboratory. The models systems were: $0 ; 5 ; 10 ; 50 ; 100 ; 250 ; 500 ; 1000$ and 2000 ppm of SPC in cooked boneless ham.

These model systems were prepared in duplicate mixing different quantities of minced cooked boneless ham with $0.2 \%$ (2000 ppm) of SPC with minced cooked boneless ham without extrinsic proteins. The cooked boneless ham with $0.2 \%$ of SPC and the cooked boneless ham without extrinsic proteins were manufactured by a local industry. The weight of each boneless ham was $3.5 \mathrm{Kg}$ and they were cooked by the system "cook in" in an oven with steam during 4:30 hs, the temperature in the center of each boneless ham reached $72^{\circ} \mathrm{C}$. Each cooked boneless ham was ground in a food processor.

The SPC was a commercial sample and it contains $63 \%$ of proteins (Kjeldahl Method).

\subsection{Commercial Meat Products}

Eight commercial meat products were analyzed: mortadellas (MP, MPA), boneless ham (JC), porcine products labelled "Fiambre de cerdo" (F, FS), and sausages $(\mathrm{CH}, \mathrm{SF}, \mathrm{SPO})$. A single batch of each product was analyzed. All the content of the package was homogenized in the samples MP, MPA, JC, F, FS, CH and SF. In the case of SPO, as each pack contained several units of the product, the sample was prepared mixing a random portion of each unit. Each commercial meat products was ground in a food processor.

\subsection{ELISA}

The detection and quantification of total milk proteins were determined with ELISA Ridascreen ${ }^{\circledR}$ Fast Soya from R-Biopharm, Veratox ${ }^{\circledR}$ Quantitative Soy Allergen Test from Neogen and AgraQuant ${ }^{\circledR}$ Soy Assay from Romer. All samples were assayed in duplicate following the protocols of each kit.

The detection (DL) and quantification (QL) limits for each kit were: ELISA Ridascreen ${ }^{\circledR}$ Fast Soya from R-Biopharm DL: $0.31 \mathrm{ppm}$ soy protein and QL: $2.5 \mathrm{ppm}$ soy protein with a quantification range of 2.5-20.0 ppm soy protein; Veratox ${ }^{\circledR}$ Quantitative Soy Allergen Test from Neogen QL: 10.0 ppm soy protein isolate with a quantification range of $10.0-100.0$ ppm soy protein isolate (SPI); AgraQuant ${ }^{\circledR}$ Soy Assay from Romer DL: $16.0 \mathrm{ppb}$ soy tripsin inhibitor and QL: $40.0 \mathrm{ppb}$ soy trypsin inhibitor with a quantification range of 40.0-1000.0 ppb soy trypsin inhibitor (STI) $[8,9,10]$

\section{Results and Discussion}

\subsection{Model Systems of Raw Meat and Cooked Boneless Ham}

It is very important to add the allergen under study before food processing [11]. Several studies confirm that incurred materials are more representative of processed products contaminated before or at some stage during processing. This is because afterwards, during processing, the allergen is exposed to physical or chemical conditions that might provoke changes on its structure, stability and solubility [12].

The used of this incurred food materials provides the capability to meaningfully evaluate processing effects on food allergen proteins in a complex food matrix and enables a critical assessment of analytical method performance between commercial ELISA kits [13].

Table 1 shows the results of soy protein content in model systems of raw meat and in model systems of cooked boneless ham with the addition of 0-2000 ppm SPC, using three ELISA kits.

As shows in Table 1 R-Biopharm kit detected above 5 ppm SPC in raw meat model systems and above 10 ppm SPC in cooked boneless ham model systems. Neogen kit detected above $250 \mathrm{ppm}$ SPC in both model systems and Romer kit detected above 100 ppm SPC in raw meat model systems and above $50 \mathrm{ppm}$ SPC in cooked boneless ham model systems.

Different extraction solutions used in different kits may account for some of the variances in the sensibility of the kits. ELISA kits based on extraction solution with SDS and 2-ME have been globally recognized for their effective extraction [14]. Surfactants and reducing agents are useful for the solubilization of insoluble proteins [15]. R-Biopharm kit uses mercaptoethanol, a reductant for protein dissociation by disulfide bond cleavage. Veratox-Neogen kit uses an extraction solution containing PBS, that could explain the lower sensibility of this kit. These results probably confirm the efficiency of the ELISA to accurately detect soy proteins when they are extracted with a solution containing mercaptoethanol. 
Table 1. Results obtained in the quantification of soy proteins using three ELISA kits in model systems of raw meat and in model systems of cooked boneless ham with the addition of 0-2000 ppm of soy protein concentrate (SPC).

\begin{tabular}{|c|c|c|c|c|c|c|}
\hline \multirow{2}{*}{$\begin{array}{l}\text { Raw and cooked } \\
\text { model systems } \\
\text { ppm SPC }\end{array}$} & \multicolumn{2}{|c|}{$\begin{array}{l}\text { Ridascreen }{ }^{\circledR} \text { Fast Soya from } \\
\text { R-Biopharm ppm soy protein }\end{array}$} & \multicolumn{2}{|c|}{$\begin{array}{l}\text { Veratox® Quantitative Soy Allergen Test } \\
\text { from Neogen ppm soy protein isolates }\end{array}$} & \multicolumn{2}{|c|}{$\begin{array}{l}\text { AgraQuant }{ }^{\circledR} \text { Soy Assay from Romer } \\
\text { ppb soy trypsin inhibitor }\end{array}$} \\
\hline & Raw & Cooked & Raw & Cooked & Raw & Cooked \\
\hline 0 & $<2.5$ & $<2.5$ & $<10.0$ & $<10.0$ & $<40.0$ & $<40.0$ \\
\hline 10 & $6.8+2.1$ & $3.6+1.1$ & $<10.0$ & $<10.0$ & $<40.0$ & $<40.0$ \\
\hline 50 & $>20.0$ & $>20.0$ & $<10.0$ & $<10.0$ & $<40.0$ & $43.2+6.6$ \\
\hline 100 & $>20.0$ & $>20.0$ & $<10.0$ & $<10.0$ & $64.3+3.2$ & $90.8+21.7$ \\
\hline 500 & $>20.0$ & $>20.0$ & $86.9+3.7$ & $53.1+17.0$ & $312.1+1.1$ & $346.2+64.5$ \\
\hline 1000 & $>20.0$ & $>20.0$ & $>100.0$ & $69.5+12.4$ & $389.7+6.9$ & $642.7+77.1$ \\
\hline 2000 & $>20.0$ & $>20.0$ & $>100.0$ & $>100.0$ & $806.7+48.0$ & $970.0+97.0$ \\
\hline
\end{tabular}

Results obtained using R-Biopharm and Veratox-Neogen kits were lower than real values. It is difficult to evaluate the correct quantification of Romer kit because the results are calculated as ppb soy tripsin inhibitor (STI). Results obtained for raw model systems were higher than those obtained for cooked model systems using R-Biopharm and Veratox-Neogen kits, while results for raw model systems were lower than those obtained for cooked model systems using Romer kit.

According to our results the heat treatment changed the results obtained of soy proteins concentrations. In the case of Romer kit the concentrations detected in cooked model systems were higher than in raw model systems and lower in the case of Neogen and R-Biopharm kits.

As already mentioned, during food processing (heat treatment) proteins might undergo denaturation, become less soluble and suffer changes altering antigen-antibody interactions. Protein immunoreactivity might be diminished or increased [13]. The main causes for the modifications in immunoreactivity are: inactivation or destruction of epitope structures, formation of new epitopes or better access of cryptic epitopes by denaturation of the native allergen [16]. All these changes could explain the different results obtained in raw and cooked model systems.

Results obtained with the three commercial kits for the same sample (for example cooked model system with 250 $\mathrm{ppm}$ ) are expressed in different units (ppm soy protein, ppm soy protein isolate or soy ppb STI), so they cannot be compared. It would be appropriate that kits report their results in the same units. The standardization of reporting units would not only make recovery studies be more comprehensible, it also facilitates kits comparison [12].

Although Elisa method is accepted as standard method for allergen measurement, these results seem to vary with manufacturer. Discrepancies in protein quantitation among different ELISA kits can be attributed to: antibody specificity, sample extraction conditions, selection of reference materials for calibration, and different specified reporting units of protein concentration [13].

\subsection{Commercial Meat Products}

The description and the declared protein ingredients of each commercial meat product are detailed in Table 2. It also shows the results obtained in the quantification of soy proteins using three ELISA kits.

For one commercial sample that did not declare soy (JC), results were below the quantification limits for the three kits used.

In sample $\mathrm{F}$ label, soy declaration was not included. However, 22.3 ppm SPI was detected using Veratox-Neogen kit and $581.0 \mathrm{ppb}$ STI using Romer kit. Accordingly, it was checked with the manufacturer whether the sample could contain an ingredient or additive with soy proteins. The manufacturer informed that the sample included an additive called "ham flavor" that declared the presence of soy in its allergen statement.

FS declared soy products and soy proteins were detected with all kits.

For two commercial samples that did not declare soy (SF, SPO), the results were $>20 \mathrm{ppm}$ soy protein using R-Biopharm kit, 67.0 and 67.8 ppm SPI, respectively, using Veratox-Neogen kit and $>1000$ ppb STI using Romer kit.

In a previous study using immunoblotting soy proteins were detected in F, SPO and SF. These results were confirmed using ELISA kits [17].

In MPA, that did not declare soy, this protein was not detected using Veratox-Neogen kit. The result with Romer kit was $448.0 \mathrm{ppb}$ STI. In a previous study soy proteins were detected in this sample using immunoblotting. It should be because of the lower sensitivity of the Veratox-Neogen kit. Immunoblotting detects soy above $100 \mathrm{ppm} \mathrm{SPC}$ and Veratox-Neogen kit detects soy above 250 ppm SPC [17].

MP declared soy protein isolate in its list of ingredients but Veratox-Neogen and Romer kits did not detect soy. According to this result it could be confirmed that a soy product was not used in this product. Occasionally some samples detail in their list of ingredients some raw materials that are not present in their composition. This could be due to changes in the raw materials used that are not reflected on the labels because they are outdated.

The presence of undeclared allergenic substances in food products and ingredients may be a risk for allergic persons. It is recommended that food industries establish effective allergen control programs to prevent the occurrence of undeclared allergens due to cross contact. The food industry should label their products declaring all the allergenic ingredients used. 
Table 2. Results obtained in the determination of soy proteins using three ELISA kits in eight commercial samples.

\begin{tabular}{|c|c|c|c|c|c|}
\hline Samples & $\begin{array}{l}\text { Description of the } \\
\text { product }\end{array}$ & $\begin{array}{l}\text { Declared protein } \\
\text { ingredients }\end{array}$ & $\begin{array}{l}\text { Ridascreen }{ }^{\circledR} \text { Fast Soya } \\
\text { from R-Biopharm ppm } \\
\text { soy protein }\end{array}$ & $\begin{array}{l}\text { Veratox }{ }^{\circledR} \text { Quantitative Soy } \\
\text { Allergen Test from Neogen } \\
\text { ppm soy protein isolates }\end{array}$ & $\begin{array}{l}\text { AgraQuant }{ }^{\circledR} \text { Soy } \\
\text { Assay from Romer ppb } \\
\text { soy trypsin inhibitor }\end{array}$ \\
\hline $\mathrm{JC}$ & Boneless ham & Porcine meat & $<2.5$ & $<10.0$ & $<40.0$ \\
\hline $\mathrm{F}$ & $\begin{array}{l}\text { Porcine product labelled } \\
\text { "pork luncheon meat" }\end{array}$ & Porcine meat & NA & 22.3 & $581.0+26.7$ \\
\hline FS & $\begin{array}{l}\text { Porcine product labelled } \\
\text { "pork luncheon meat" }\end{array}$ & $\begin{array}{l}\text { Porcine meat and soy } \\
\text { protein isolate. }\end{array}$ & $>20.0$ & $>100.0$ & $970.0+18.2$ \\
\hline SF & "Sopressata" & $\begin{array}{l}\text { Bovine meat, wheat } \\
\text { gluten }\end{array}$ & $>20.0$ & $67.0+1.3$ & $>1000.0$ \\
\hline SPO & $\begin{array}{l}\text { Chicken cooked } \\
\text { sausages }\end{array}$ & Chicken meat & $>20.0$ & $67.8+2.04$ & $>1000.0$ \\
\hline MPA & Mortadella & $\begin{array}{l}\text { Bovine meat and porcine } \\
\text { meat }\end{array}$ & NA & $<10.0$ & $448.0+17.0$ \\
\hline MP & Mortadella & $\begin{array}{l}\text { Bovine meat, porcine } \\
\text { meat, soy protein isolate }\end{array}$ & $<2.5$ & $<10.0$ & $<40.0$ \\
\hline $\mathrm{CH}$ & Dry Sausage & $\begin{array}{l}\text { Bovine meat, porcine } \\
\text { meat }\end{array}$ & NA & $<10.0$ & NA \\
\hline
\end{tabular}

NA: not analyzed

According to these results Elisa kits were found to be particularly suitable for routine detection of soy as an allergen in food products. Since the analytical procedure is quite easy and fast, so it could be useful for a quick check of possible contamination or residues from soy. The main disadvantage is that industrial processing could destroy protein structure, and for this reason results related to processed foods should be regarded as presumptive only, never as absolute [18].

\section{Conclusions}

It is very important to choose the right ELISA kit for the detection of soy proteins. R-Biopharm kit was the most sensitive one for the samples analyzed. In all kits that have been tested, soy detection was affected by thermal processing.

Some kits have been found useful to detect soy in commercial products not declaring soy in their labels. Soy presence might be because it was added as a non-declared ingredient or due to cross contact with soy products in the manufacturing process.

The food industry should be responsible for the declaration of soy on the labels of their products, to protect sensitive consumers.

\section{Acknowledgements}

The authors are grateful to VAES S. R. L. for bringing samples of known composition for analysis.

This work was partially financiated by the Universidad de Buenos Aires (UBACyT 20020120100175BA)

\section{References}

[1] Ward R. 2014. Chapter 1: Introduction to food allergy. In Flanagan S, Handbook of Food Allergen Detection and Control. Woodhead Publishing. Cambridge, UK.
[2] López, L. B., Greco, C. B., Ronayne de Ferrer, P., Valencia, M E. 2006. Identification of extrinsic proteins in boneless cooked ham by SDS-PAGE: detection level in model systems. Archivos Latinoamericanos de Nutrición. 56 (3): 282.

[3] Argentine Food Code, 2016.

[4] http://www.anmat.gov.ar/alimentos/codigoa/Capitulo_V.pdf.

[5] Access: 06/09/16.

[6] López, L. B., Binaghi, M. J. Greco, C. B., Mambrín, M. C., Cellerino, K., Valencia, M. E. 2010. Salted sausage and dried sausages: detection by electrophoresis of meat species and extrinsic proteins aggregate. Diaeta. 28 (131): 7.

[7] Act $\mathrm{N}^{\circ} 102$ CONAL. 2014.

[8] http://www.conal.gob.ar/actas/Acta_102_AnexoI.pdf. Access: $10 / 07 / 2016$.

[9] Act N 103 CONAL. 2014.

[10] http://www.conal.gob.ar/actas/Acta_103_AnexoI.pdf. Access: $10 / 07 / 2016$

[11] Act $\mathrm{N}^{\circ} 111$ CONAL. 2016.

[12] http://www.conal.gob.ar/actas/Acta_111.pdf Access: 06/ $09 / 2016$.

[13] R-Biopharm RIDASCREEN ${ }^{\circledR} \quad$ FAST Soya. 2016. http://www.r-biopharm.com/products/food-feed-analysis/aller gens/soya/item/ridascreenfast-soya Access: 06/09/2016.

[14] Neogen Veratox ${ }^{\circledR}$ quantitative Soy Allergen test. 2014. http://www.neogen.com/FoodSafety/pdf/ProdInfo/V-Soy.pdf. Access: 27/02/2016.

[15] Romer AgraQuant ${ }^{\circledR} \quad$ Soy Assay. 2016. https://shop.romerlabs.com/en/AgraQuant-ELISA/AgraQuantAllergens/AgraQuant-ELISA-Soy Access: 01/ 08/2016.

[16] Diaz Amigo C. 2010. Towards a Comprehensive Validation of ELISA Kits for Food Allergens. Case 2- Milk. Food Analytical Methods. 3: 351-356. 
[17] Diaz Amigo C. and Popping B. 2010. Analytical Testing as a Tool for the Enforcement of future Regulatory Thresholds for Food Allergens. Journal of AOAC International. 93 (2): 434-441.

[18] Parker C., Khuda S., Pereira M., Ross M., Fu T., Fan X., Wu Y., Williams K., DeVries J., Pulvermacher B., Bedford B., Zhang X., Jackson L. 2015. Multi-allergen Quantitation and the Impact of Thermal Treatment in Industry-Processed Baked Goods by ELISA and Liquid Chromatography-Tandem Mass Spectrometry. J Agric food chem. 63: 10669-10680.

[19] Ito K, Yamamoto T, Oyama Y, Tsuruma R, Saito E, Saito Y, Ozu T, Honjoh T, Adachi R, Sakai S, Akiyama H, Shoji M. 2016. Food allergen analysis for processed food using a novel extraction method to eliminate harmful reagents for both ELISA and lateral-flow tests. Anal Bioanal Chem. 408 (22): 5973-84.

[20] Watanabe Y, Aburatani K, Mizumurz T, Sakai M, Muraoka S,
Mamegosi S, Honjoh T. 2005. Novel ELISA for the detection of raw and processed egg using extraction buffer containing a surfactant and reducing agent. J Immunol Methods. 300: 115-123.

[21] Besler M., Steinhart H., Paschke A. 2001. Stability of food allergens and allergenicity of processed food. J cromatogr B: Biomed Sci Appl. 756 (1-2): 207-228.

[22] Cellerino Karina, Binaghi María Julieta, Cagnasso Carolina Elisa, Docena Guillermo, López Laura Beatriz. 2012. Comparison of SDS-PAGE and Immunochemical methods for the detection of soy proteins in raw and cooked meat products. Revista Chilena de Nutrición 39 (3): 52-57.

[23] Gatti M and Ferretti C. 2010. Chapter 17: Soy Allergen Detection, en Popping B, Diaz Amigo C, Hoenicke K, Molecular Biological and immunological techniques and applications for food chemists. John Wiley \& Sons, Inc., Canada. 